\title{
IRT survey for the quality control of FRP reinforced r.c. structures
}

by P. Corvaglia*, A. Largo*

* Department of Materials and Structures Engineering - Consorzio CETMA, Brindisi, Italy; mobile: +39-0831449111, fax:+39-0831-449120, paolo.corvaglia@cetma.it, alessandro.largo@cetma.it

\begin{abstract}
Externally bonded Fibre Reinforced Polymers (FRPs) are widely used for strengthening of existing structures in recent years. However, the success of FRP reinforcement techniques is mainly subjected to the properly application of the FRPs, so a key role is played by the quality control of the application, to be performed by non - destructive techniques. At this aim, CETMA developed an InfraRed (IR) Thermography procedure and a post processing methodology able to detect and measure the area of bonding defects at the FRP - substrate interface. In this paper, the in - situ validation of the developed procedure on two r.c. structures retrofitted with FRP materials is presented.
\end{abstract}

Key words: Thermography, FRP, r.c. structures, quality control, bonding

\section{Introduction}

Since its first applications in Europe and Japan in the 1980s, the use of bonded repair and retrofit of concrete structures with fibre reinforced polymer (FRP) systems has progressively increased. Thanks to their light weight, ease of installation, durability, minimal labour costs and site constraints, high strength/weight and stiffness/weight ratios, FRP repair systems can provide an economically viable alternative to traditional repair systems and materials, such as steel plate bonding, steel or concrete jackets, external post - tensioning and section enlargement.

FRP systems can be used either to rehabilitate and restore the strength of a weakened, damaged, or deteriorated structural member or to retrofit and strengthen a sound structural member to resist higher loads in case of a design or construction error, in case of a change in use or loading, or for a seismic upgrade.

Additionally, these materials are readily available in several forms, ranging from factory made laminates to dry fibre sheets, that can be wrapped to conform to the geometry of a structure. The relatively thin profile is often desirable in applications where aesthetics or access is a concern.

However, it is widely accepted that quality of construction is one of the most important factors that affect long - term performance of FRP repair systems. In order to assure an effective FRP reinforcement, perfect adhesion between FRP and substrate (concrete or masonry) must be obtained; for this reason, it is essential to assess the quality of bonding with a Quality Control (QC) process, starting before the installation of the system (specific procedures for track and inspection all FRP components prior to installation, inspection of all prepared surfaces prior to FRP application) and continuing through and after the application (inspection of the work in progress to assure conformity with specifications, obtaining quality assurance samples, inspection of all completed work, performing tests for approval, repair of any defective work,...).

For these purposes, visual inspection, acoustic tap testing, laboratory testing of witness panels or resin samples, direct pull - off testing are the most applicable methods of QC. Tap test seems to be the easier method to be used for the identification of defects at the FRP - substrate interface or inside the FRP; this because the infrastructures inspectors are quite familiar with tap tests and simply need to be trained to hear the difference between bonded and unbonded laminates, which is somewhat similar to the difference between sounding and damaged concrete. However scanning very large areas of reinforced structures with tap test could be very expensive in terms of time and safety.

Infrared (IR) thermography can be a fast, reliable and confident non destructive testing technique for the evaluation of bonding defects in FRP - reinforced concrete structures.

However, the set - up of IR technique for the detection of a particular defect (delamination, lack of bonding, ...) in an FRP - reinforced r.c. structure needs a specific calibration, leading to the proper definition of the operational parameters (active/passive approach, distances, time - windows, ...).

Based on the results obtained in a large experimental program, an IR Thermography procedure, easily applicable on - site, was developed. After the definition of acceptance criteria and reparation techniques for the defects, also a post processing software tool able to clearly define the defect contour was developed. This allows measuring the area of the bonding defect and then to compare it with the acceptance criteria, in order to establish whether the defect is acceptable or not, and, in case, what is the best way to repair it. 


\section{Acceptance criteria and repairing techniques}

According to the QC procedure, all the installed FRP areas shall be visually inspected for detection of any defects, such as:

1. voids and air encapsulation between concrete and layers of primer, resin, or adhesive and within the FRP system itself;

2. delaminations between layers of FRP system;

3. broken or damaged edges of the FRP system;

4. wrinkling and buckling of fibre and fibre tows;

5. discontinuities due to fracture of fibres, breakage in the fabric, or cracks in pre - cured shells;

6. cracks, blisters, and peeling of the protective coating;

7. resin - starved areas or areas with non - uniform impregnation or wet - out;

8. under cured resin;

9. incorrect fibre orientation.

Acceptability of bonding defects depends on the size, location, and number of defects in a specific area while the repair methods depend on the type of material, the form of degradation, and the level of damage.

In the following, the conditions and types of defects that require repair and the acceptable methods of repair are specified. Minor delaminations may be repaired by epoxy resin injection, middle level damages, including localized FRP laminate cracking or abrasions that affect the structural integrity of the laminate, should be repaired by bonding FRP patches (with the same characteristics, such as thickness and ply orientation, as the original laminate) over the damaged area. Major damages (including peeling and debonding of large areas) may require removal of the affected area, reconditioning of the cover concrete, and replacing the FRP laminate. More in detail:

1. Epoxy Injection of Small Defects: small entrapped voids or surface discontinuities no larger than $6 \mathrm{~mm}$ in diameter (Type 1, area $<0.3 \mathrm{~cm}^{2}$ ) naturally occur in mixed resin systems, shall not be considered defects and require no corrective action unless they occur next to edges ${ }^{1}$ or when there are more than five such defects in an area of $1 \mathrm{~m}^{2}$. Small defects of size between 6 and $30 \mathrm{~mm}$ in diameter (Type 2, $0.3 \mathrm{~cm}^{2}<$ area $<7 \mathrm{~cm}^{2}$ ) shall be repaired using low - pressure epoxy injection as long as the defect is local and does not extend through the complete thickness of the laminate in case of multiple - ply FRP systems. If any delamination growth is suspected between the FRP plies due to injection, the procedure shall be halted, and repair shall follow the "Patching of Minor Defects" procedure;

2. Patching of Minor Defects: minor damages to the FRP system may include cracking, abrasion, blemishes, chips, and cuts. The FRP patches should have the same characteristics (e.g., thickness, fibre orientation, ply stacking, and resin type) as the original laminate over the damaged area of which it will be bonded. Extending the FRP patch on all sides of the removed area helps with the load transfer. Minor defects are those with diameters between $30 \mathrm{~mm}$ and $100 \mathrm{~mm}$ (Type $3,7 \mathrm{~cm}^{2}<$ area $<8 \mathrm{~cm}^{2}$ ), and frequency of less than five per any unit surface area of $3 \mathrm{~m}$ length or width. The area surrounding the defects shall be removed to an extent of at least $25 \mathrm{~mm}$ on all sides, wiped clean and thoroughly dry. The area should be patched by adding an FRP patch of the same type of the original laminate and extending at least $50 \mathrm{~mm}$ on all sides of the removed area. Repair can also be conducted using the procedure in Replacement of Large Defects.

3. Replacement of Large Defects: large defects are generally indications of significant debonding between layers, lack of adhesion to the concrete substrate, or extended moisture entrapment causing resin degradation. Large defects should be carefully examined, since they may be symptomatic of either significant short - term degradation or poor quality of materials or installation. If the extent of the defect is large and in areas critical to the structural integrity, it may be advisable to completely remove and reapply the entire FRP system. Defects larger than $100 \mathrm{~mm}$ in diameter (Type 4, area $>80 \mathrm{~cm}^{2}$ ) shall be carefully marked and scarified out extending to a minimum of $50 \mathrm{~mm}$ on all sides. For multi - ply FRP systems, it should be scarified progressively through the layers until past the defective area. If the defect extends to the first FRP ply adjacent to the concrete, the entire thickness of FRP and primer should be removed. Concrete should be prepared and primer applied, after having checked that the surface is clean and dry. Procedures for the application of a new system should be followed when applying FRP in the scarified area, except add an additional layer extending a minimum of $150 \mathrm{~mm}$ on all sides of the scarified area as a patch. After curing, the protective coating should be applied over the entire area.

\footnotetext{
${ }^{1}$ Defects at edges or regions of discontinuity, no matter how small, can serve as stress risers that lead to rapid delaminations and growth of other types of defects. Care should be taken to ensure that the internal pressure caused between FRP layers due to injection does not cause further delaminations. Large disbonds close to the edge should not be injected but should be cut open and patched.
} 


\section{IRT procedure calibration}

The IRT survey calibration was performed in the technological laboratory of CETMA; according to literature indications, some FRP - reinforced concrete samples were accurately prepared, imposing acceptable defects with different shapes and dimensions at the FRP - substrate interface. For example, air void on the order of 3.2 $\mathrm{mm}$ diameter and delaminations of less than $13 \mathrm{~cm}^{2}$, with a maximum of 10 delaminations per $1 \mathrm{~m}^{2}$, are allowed.

Two types of defects with different dimensions were imposed (see Fig. 1):

- delaminations (by the interposition of two bonded Teflon foils)

- $\quad$ defects $\mathrm{n}^{\circ} 5$ and $\mathrm{n}^{\circ} 6(100 \mathrm{~mm} \times 10 \mathrm{~mm})$

- $\quad$ defects $\mathrm{n}^{\circ} 1$ and $\mathrm{n}^{\circ} 4(65 \mathrm{~mm} \times 20 \mathrm{~mm})$;

- $\quad$ defects $\mathrm{n}^{\circ} 7$ and $\mathrm{n}^{\circ} 8(40 \mathrm{~mm} \times 40 \mathrm{~mm})$;

- $\quad$ defects $\mathrm{n}^{\circ} 2$ and $\mathrm{n}^{\circ} 3(20 \mathrm{~mm} \times 20 \mathrm{~mm})$;

- $\quad$ lack - of - bonding of the FRP (by a simple Teflon foil)

- $\quad$ defects $\mathrm{n}^{\circ} 13$ and $14(100 \mathrm{~mm} \times 10 \mathrm{~mm})$;

- $\quad$ defects $\mathrm{n}^{\circ} 11$ and $12(65 \mathrm{~mm} \times 20 \mathrm{~mm})$;

- $\quad$ defects $\mathrm{n}^{\circ} 15$ and $16(40 \mathrm{~mm} \times 40 \mathrm{~mm})$;

- defects $\mathrm{n}^{\circ} 9$ and $10(20 \mathrm{~mm} \times 20 \mathrm{~mm})$.

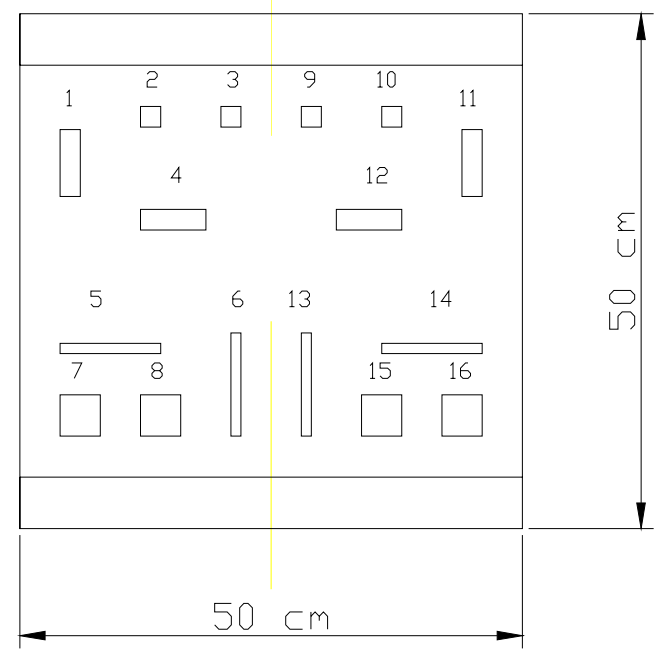

Fig. 1 Imposed known defects

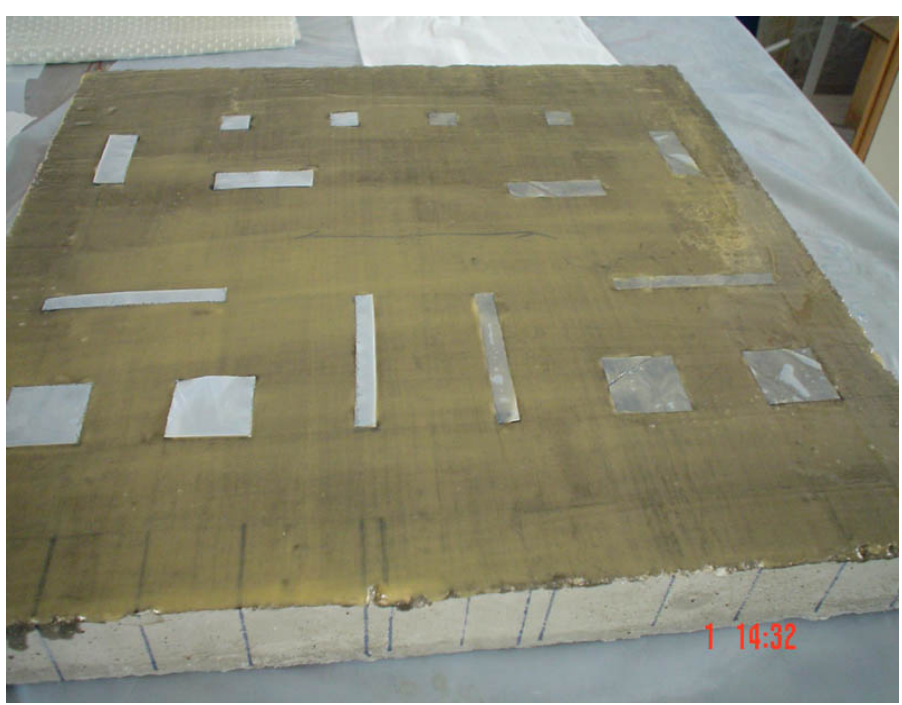

Fig. 2 Sample preparation visibility:

Four important set - up parameters were investigated and defined in order to obtain the best defect

1. thermocamera - sample distance;

2. heating source - sample distance;

3. "impulsive heating" time, named Heating Time (HT);

4. time, after the heating step, at which the thermogram should be recorded, named Time of Observation (TObs).

This experimental campaign led to the calibration of an IR yard - friendly methodology, defining all the necessary operative parameters.

The sample surface was analyzed with to different methods: pulsed thermography (PT) and lock - in thermography (LT). In this paper, only the results obtained from the PT survey are reported.

A commercial halogen lamp with a nominal power of $500 \mathrm{~W}$ was used; the adopted thermocamera was a commercial microbolometric FLIR System with a 320 × 256 Focal Plane Array. The test set - up was realized as cheap as possible, in order to develop an experimental procedure that could be easily applied on the field and not only in research laboratories.

After the definition of acceptance criteria and reparation techniques for the defects, CETMA developed a Matlab routine for the thermogram post processing in order to measure the area of bonding defects at the FRP - 
substrate interface. Only in this way it's possible to establish whether a defect can be acceptable or not, and, in case, what is the best way to repair it.

\section{Calibration results}

Thermographic data were processed with Almond's half maximum contrast method; a typical thermogram of the CFRP - reinforced sample is presented in Fig. 3. The investigated parameters were the "impulsive heating" time (HT) and the Time of Observation (TObs). Partial results are reported in Fig. 4 related to defect $n^{\circ} 3$.
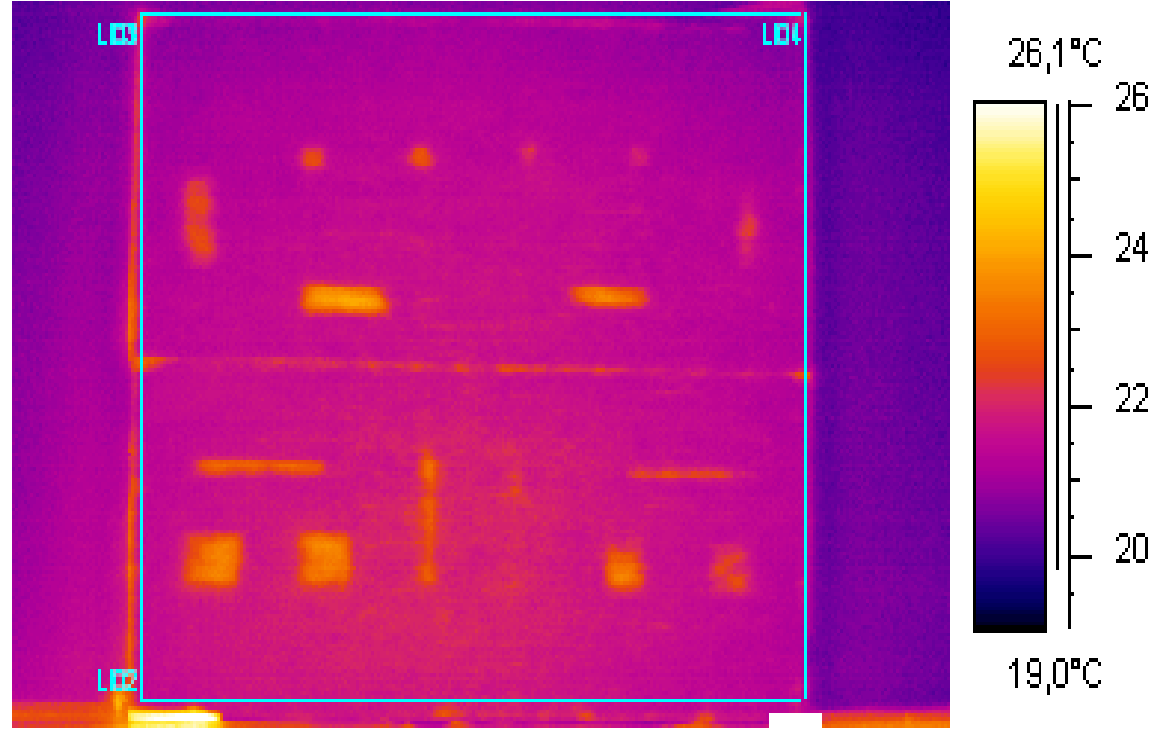

Fig. 3 Thermogram of the CFRP sample with imposed defects

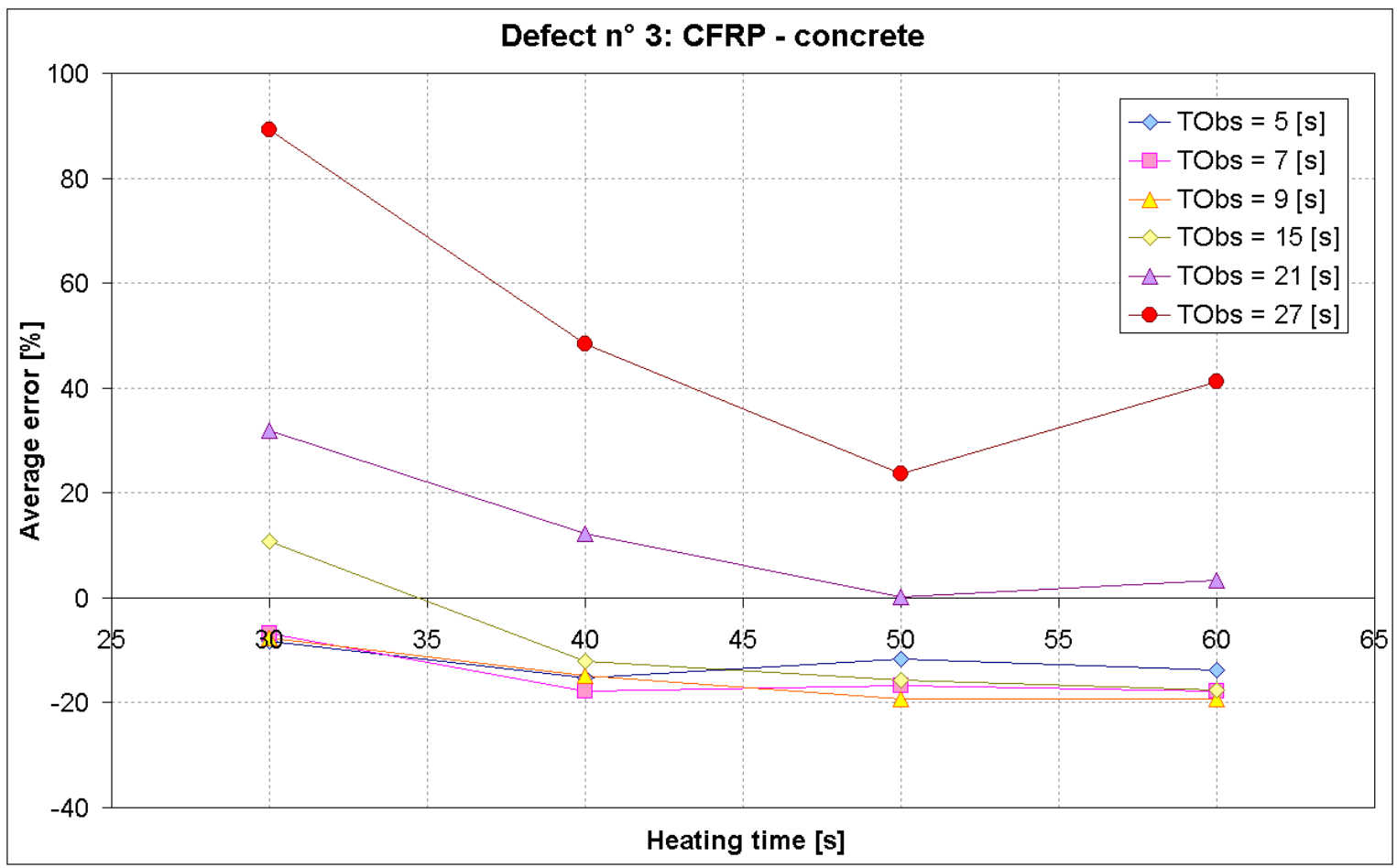

Fig. 4 Percentage error in the assessment of defect $n .3$ for different experimental set-ups

Some interesting remarks can be pointed out:

1. the error (defined as the ratio between the difference of the estimated and the real number of pixels relative to a defective area, and the real number of pixels relative to the same defective area) increases with increasing TObs; 
2. statistical ANalysis Of VAriance (ANOVA) indicates that the investigated parameters (TObs and HT), have no mutual influence;

3. thermograms recorded at a TObs of more than about $20 \mathrm{~s}$ are not useful;

4. the lower percentage error can be obtained with a HT period in the range $40-60 \mathrm{~s}$.

\section{IRT survey results} materials.

The developed IRT procedure was applied for quality control of two r.c. structures reinforced with FRP

The former, the ex Law Courts of Sant'Angelo dei Lombardi (in the municipal district of Avellino, Italy), retrofitted with GFRP sheets after the catastrophic Irpinia earthquake (magnitude 6.9) of 23rd November, 1980.

The latter, an Italian highway r.c. single span bridge structure, seismic upgraded with CFRP materials according to the Italian law OPCM 3431.

The adopted thermocamera was a commercial microbolometric FLIR System with a $320 \times 256$ Focal Plane Array. Thermographic data were processed with Almond's half maximum contrast method; a particular Matlab routine was implemented in order to apply Almond's procedure to the whole thermogram and to measure the exact extension of the detected defects.

For comparative testing, other traditional NDT techniques (visual inspection and coin - tap) were used for the quality control of the FRPs application. It can be pointed out that IR thermpography allows a quicker detection not only of all the defects detectable also with other traditional NDTs but also of a set of other smaller defects, otherwise not detectable, but anyhow potentially dangerous for structural safety.

\subsection{Case study \#1: ex Law Courts of Sant'Angelo dei Lombardi}

The building was realized at the beginning of the seventies; it has a " $Y$ " shaped plan and is constituted by three levels with an overall height of ten meters. The structure is made up of plane frames connected by perpendicular beams which permit to assume a spatial behaviour.

The structure was seismically upgraded with a combination of traditional and innovative techniques (confinement of possible plastic hinges in columns, total or $U$ - shaped wrapping of beams and beam - column joints with FRP materials), in order to obtain ductility and strength enhancement at the same time.

The structure reinforced with GFRP materials was mainly investigated with the infrared thermography survey procedure developed; indoor surveys were performed with an active approach, using a commercial halogen lamp with a nominal power of 1000 [W], while outdoor surveys were performed using the sun as heating source, both during the heating (in the morning) and cooling (in the evening) period.

In the following (Fig. 5, indoor and Fig. 6, outdoor) two examples of thermograms of the GFRP reinforced structure are presented; especially in Fig. 5 a lot of defects of different shapes and dimensions were identified.

This was probably caused by an improper use, during the placement of the FRP sheets, of the stiff rubber roller (which should help the adhesive to completely penetrate through the fibres of the fabric) and of the aluminium roller with a worm screw (which should help to completely eliminate air bubbles formed during application). All the defects were classified as Type 3.

However, in this case, considering the number and distribution of defectiveness all along the reinforced area, even if every single defect could be separately repaired, it was considered advisable to completely remove and reapply the entire FRP system.
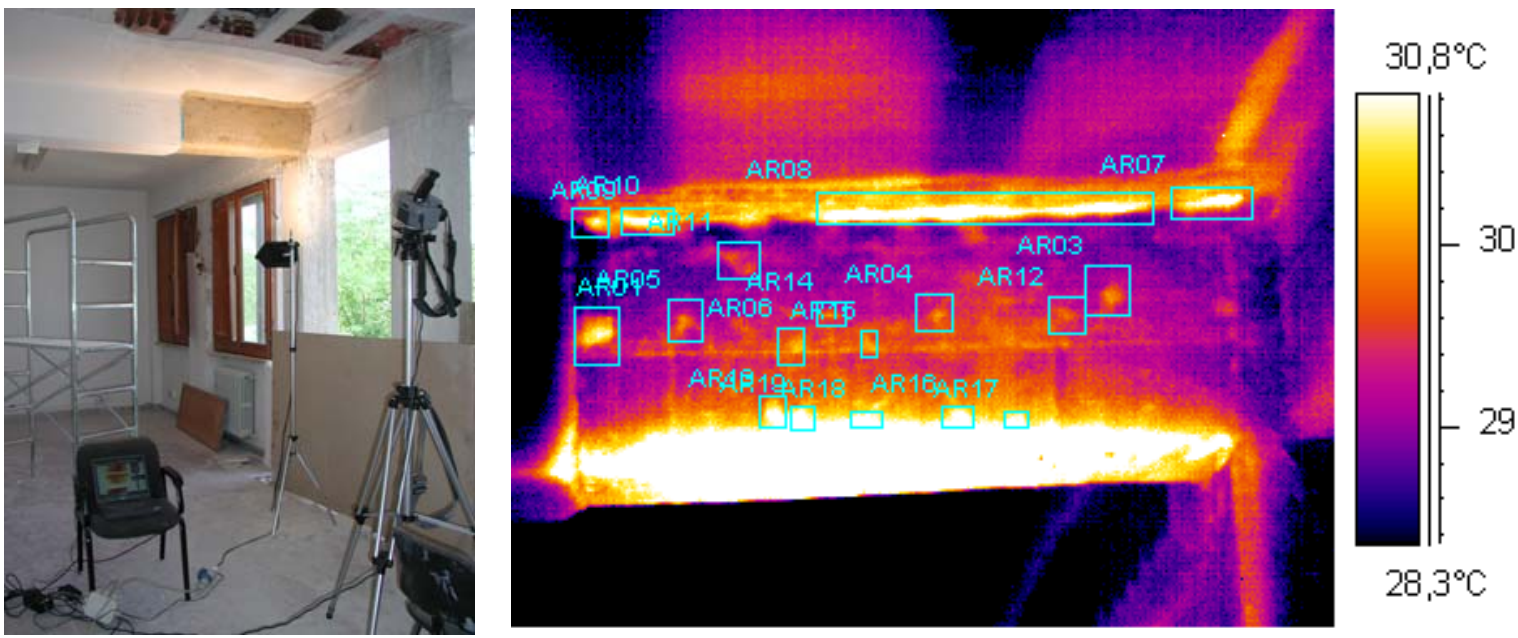

Fig. 5 Indoor IRT survey of an r.c. structure reinforced with GFRP sheets 
In Fig. 6, a thermogram recorded during an outdoor IRT survey is reported; for the whole part of the GFRP reinforced beam - column joint a perfect adhesion between the glass fibres sheets and the concrete substrate can be pointed out. However, the IRT procedure was able to identify some small bonding defects on the upper part of the joint. This kind of defect, generally caused by air entrapment, have a lower thermal inertia with respect to the GFRP - concrete interface; for this reason they appear hotter than the surrounding materials during the heating phase (Fig. 5), and colder during the cooling phase (Fig. 6).

Although the defects were classified at the limit between a Type 2 and a Type 3 defect, in case of contact - critical FRP application (e.g. columns or joints wrapped for confinement), low - pressure epoxy injection can be a valuable method for repairing.
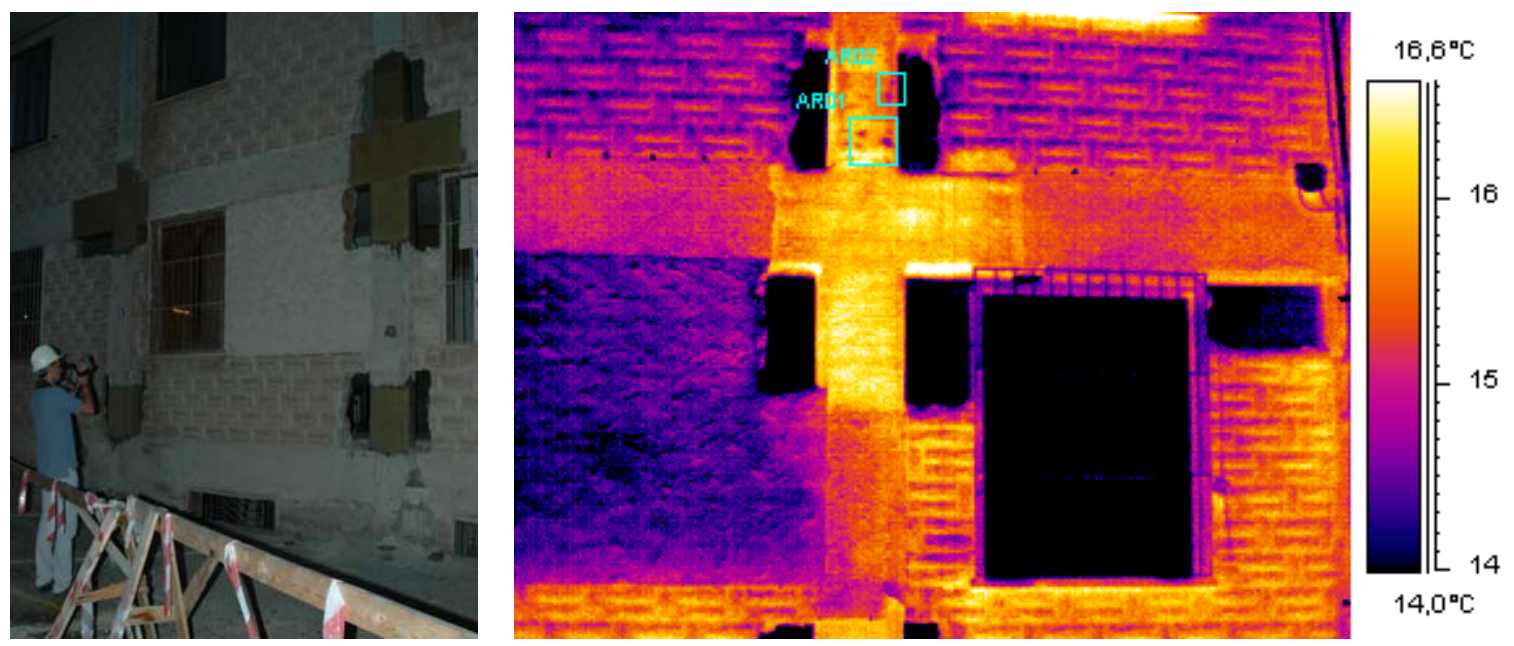

Fig. 6 Outdoor IRT survey of an r.c. structure reinforced with GFRP sheets

\subsection{Case study \#2: highway r.c. single span bridge}

The inspected bridge (named "Torrente Casale", part of the Salerno - Reggio Calabria Italian motorway), built in the seventies, was recently enlarged (2001) in order to satisfy the new traffic demands.

Due to the recent issuing of a new seismic Italian code, it was decided to assess the bridge capacity, both for gravity and seismic loads, in relation with the new design provisions.

Once the bridge geometry and the material mechanical properties were determined, a theoretical analysis was performed showing that the bridge piers were not adequate to bear the new seismic actions. Thus, an innovative rehabilitation technique based on the combined use of Carbon Fibre Reinforced Polymer (CFRPS) and Steel Reinforced Polymer (SRPs) was adopted.

The reinforced structure was investigated with the developed infrared thermography survey procedure; all surveys were performed with an active approach, using a commercial halogen lamp with a nominal power of 1000 [W].

In the following two representative results are reported, as an example.
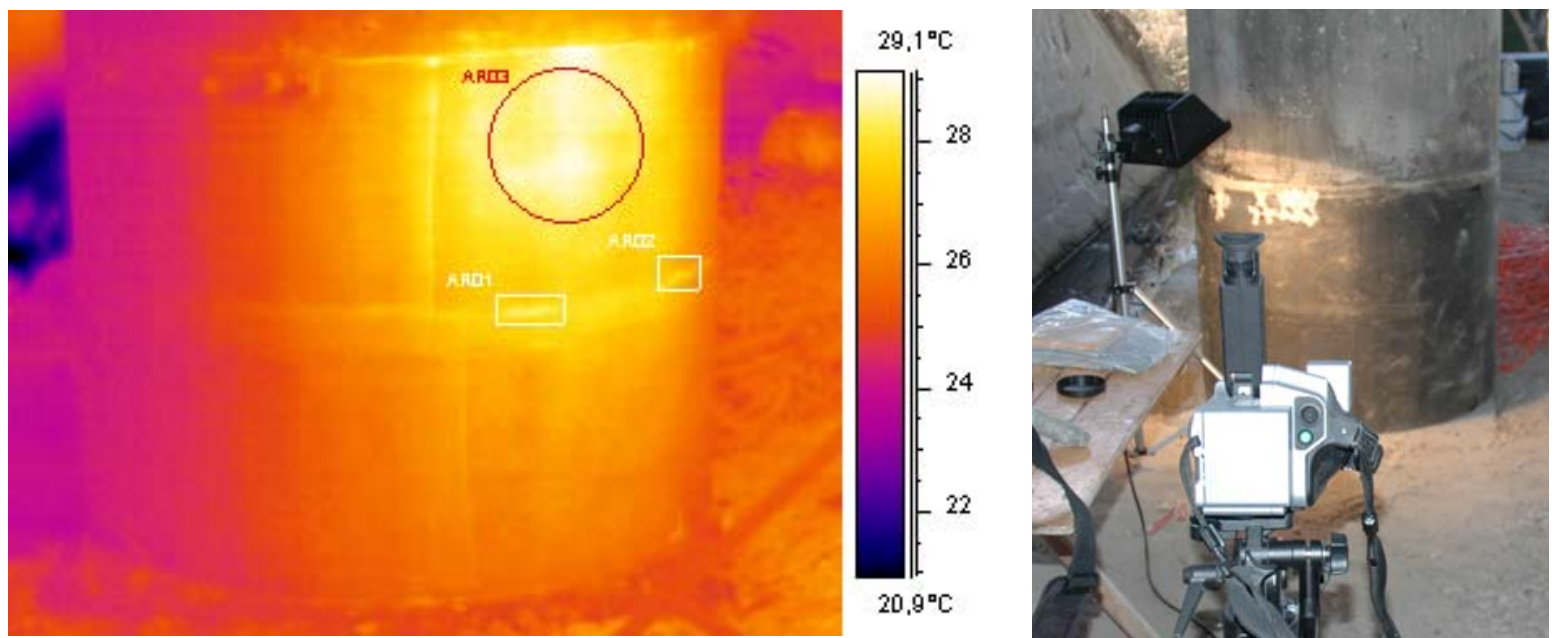

Fig. 7 IRT survey of an r.c. structure reinforced with CFRP and SRP materials 
In Fig. 7 two types of defect are described.

The first type (in white square in Fig. 7) is caused by the longitudinal joining of two CFRP sheet. When applying multiple plies of FRP sheets for columns wrapping, or when two strips need to be joined longitudinally, it is necessary to create an overlapping of at least $20 \mathrm{~cm}$. Overlapping is not necessary for the width of the fabric because the different strips of fabric can simply be applied one next to the other. Nevertheless, for the presented case study, the strategy of overlapping the two CFRP strips, along the width, for $3 \mathrm{~cm}$, was adopted (this is also evidenced in Fig. 8). According to the IRT survey results, it can be concluded that this kind of approach can cause a "step effect" resulting in a lot of air inclusion all along the column diameter. However, these kind of defects are very often characterized by a low aspect ratio and can be easily repaired using low - pressure epoxy injection.
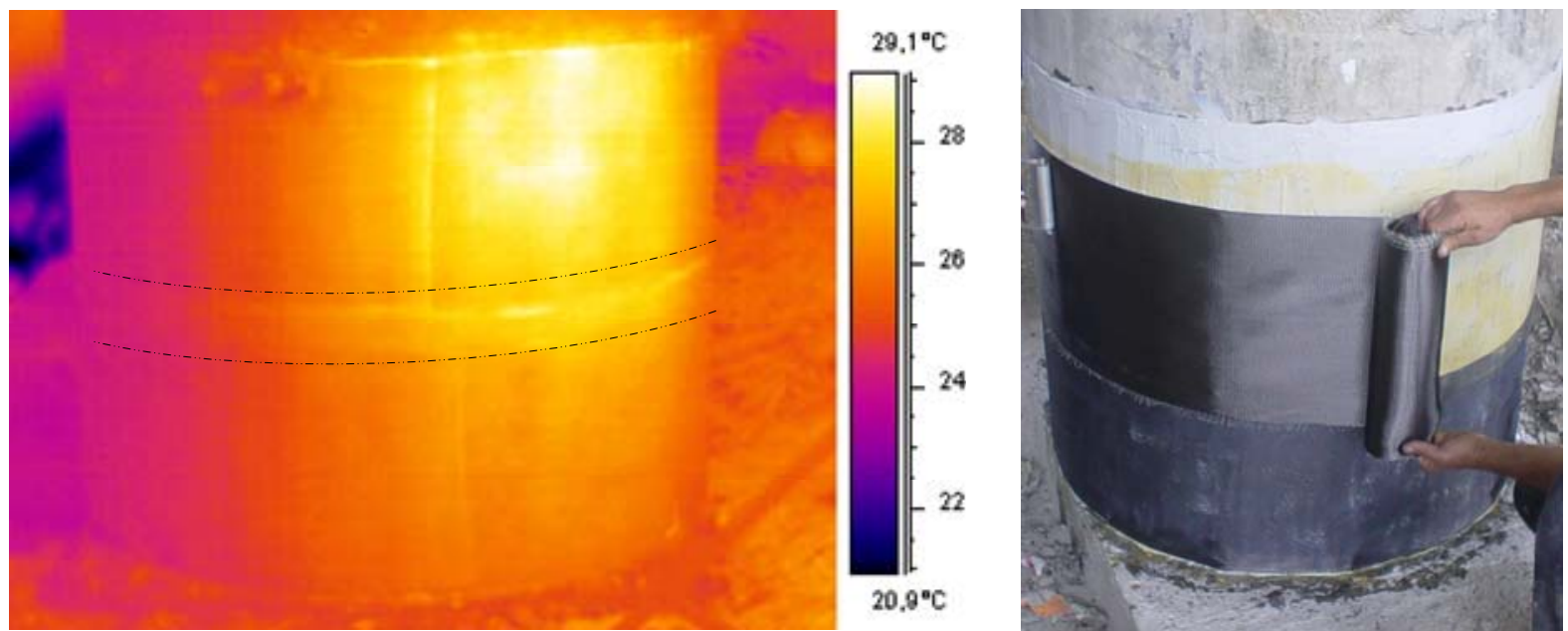

Fig. 8 CFRP strip transversal overlapping
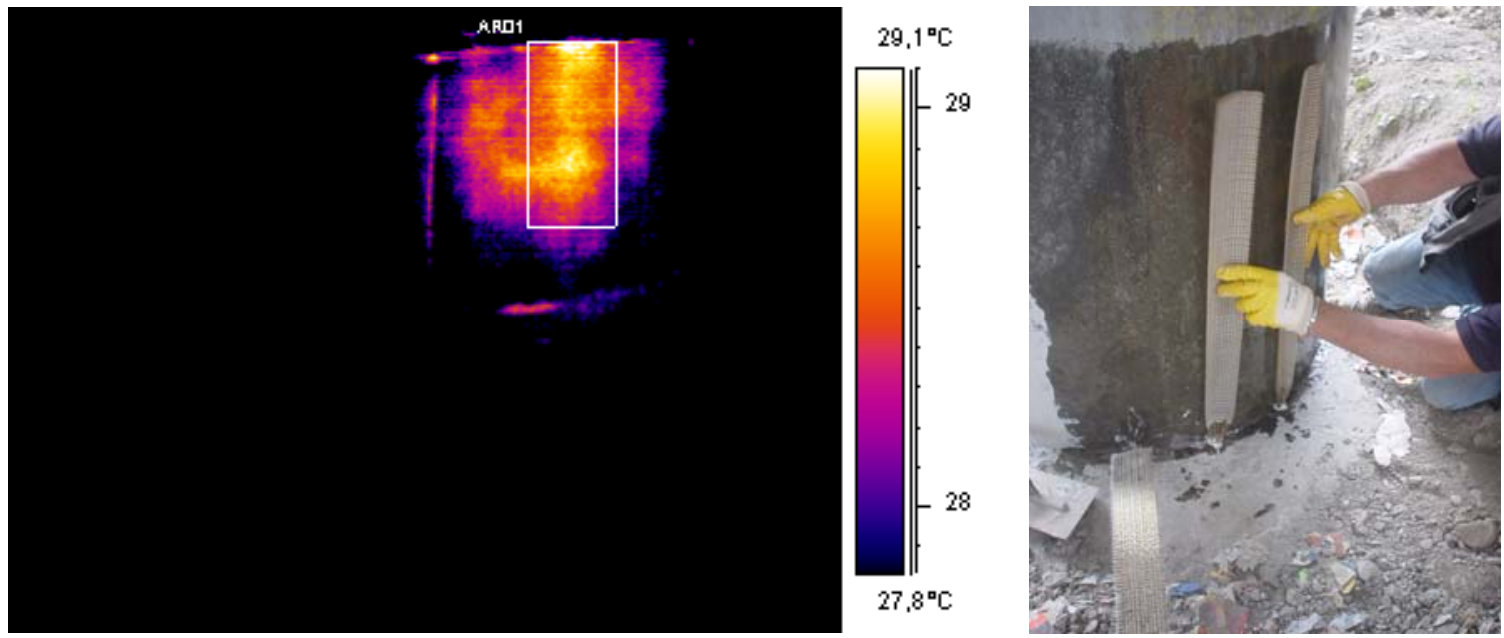

Fig. 9 Application of SRP reinforcement

The second type of defect (evidenced in the red circle in Fig. 7 and in the white rectangle in Fig. 9, left) is most probably due to the presence of the SRP reinforcement (applied between the concrete and the CFRP sheet, as described in Fig. 9, right) and can be classified as a Type 4 defect. However, considering that the debonded zone is located in a reinforced area designed as "witness panel" (i.e. not resulting from the design of the reinforcement but strengthened only to perform other tests, like direct pull - off test), it can be easily repaired with low - pressure epoxy injection.

\subsection{QC survey interpretation and repairing indications}

All installed areas were inspected for defects; summarizing tables (like the following) were then written out including the indications of:

1. site,

2. date, 
3. inspected structural elements,

4. non destructive techniques applied and their results,

5. repairing suggestions.

In particular, thanks to the thermograms post - processing procedure developed, every defect was quantified in terms of debonded area and a specific repairing technique was suggested for each defect. However, beyond the indications for each defect, a global opinion about the whole status of the intervention was also given. In some cases, especially when many defects were detected, even if the repairing of every deboned area could be a valuable strategy, the removal and subsequent reapplication of the reinforcement was suggested, in terms of easiness of intervention.

Table 1. QC survey summarizing table and repairing indications

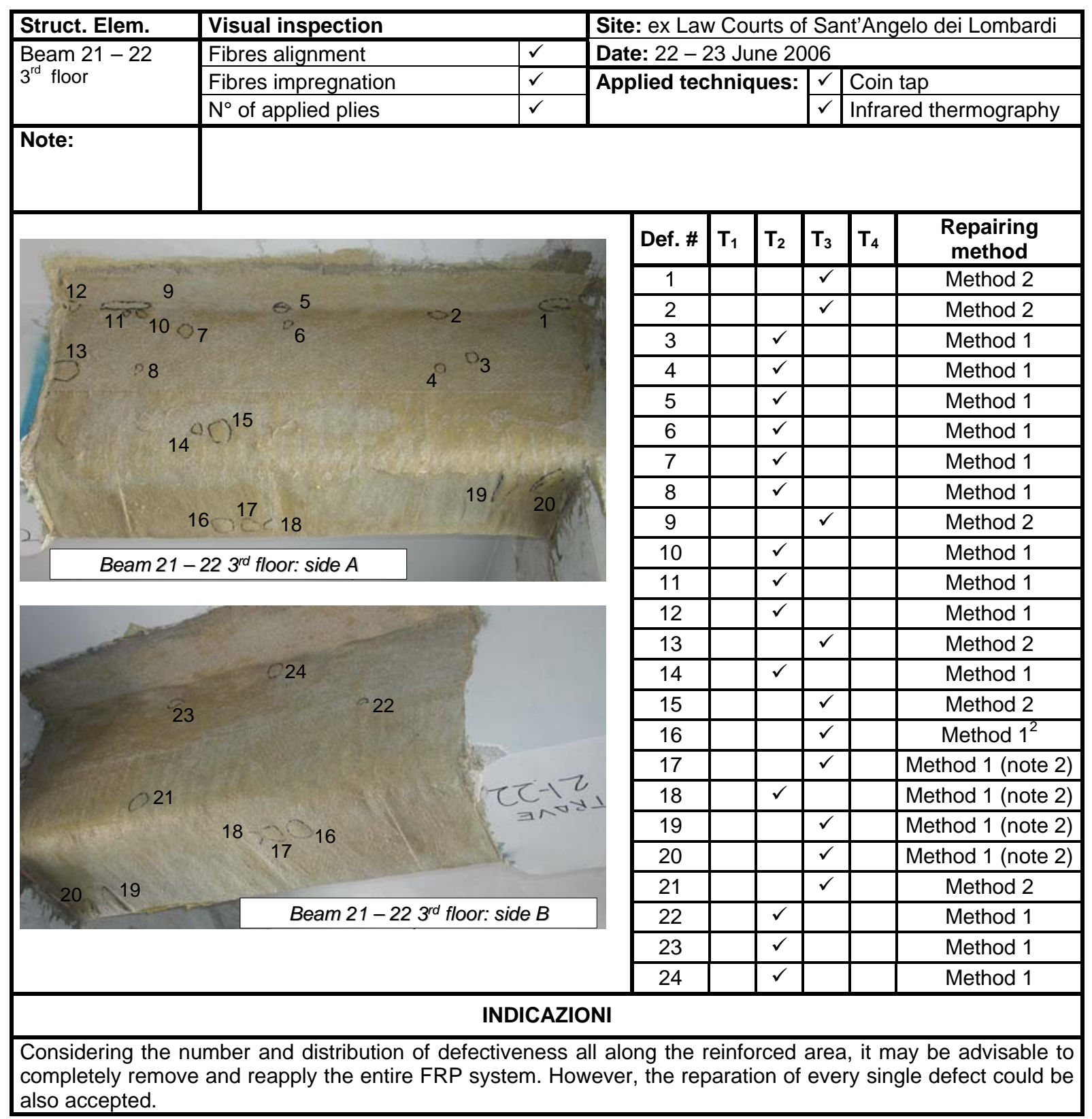

\footnotetext{
${ }^{2}$ In this zone the GFRP fibres have not any structural function in terms of shear strengthening
} 


\section{Conclusions}

In this work a reliable and confident non - destructive testing technique, based on infrared thermography, was developed as a tool for the evaluation of hidden defects in FRP - reinforced concrete structures.

It is widely recognized that the quality of construction is one of the most important factors that affect long term performance of FRP repair systems. In particular, in order to assure an effective FRP reinforcement, perfect adhesion between FRP and substrate (concrete or masonry) must be obtained; for this reason, it is essential to assess the quality of bonding with a Quality Control (QC) process, starting before the installation of the system (specific procedures for track and inspection all FRP components prior to installation, inspection of all prepared surfaces prior to FRP application) and continuing through and after the application (inspection of the work in progress to assure conformity with specifications, obtaining quality assurance samples, inspection of all completed work, performing tests for approval, repair of any defective work,...).

According to the developed QC procedure, all the installed FRP areas should be visually inspected for detection of any defects. Acceptability of bonding defects depends on the size, location, and number of defects in a specific area, while the repair methods depend on the type of material, the form of degradation, and the level of damage.

For example, minor delaminations may be repaired by epoxy resin injection, middle level damages, including localized FRP laminate cracking or abrasions that affect the structural integrity of the laminate, should be repaired by bonding FRP patches (with the same characteristics, such as thickness and ply orientation, as the original laminate) over the damaged area; major damages (including peeling and debonding of large areas) may require removal of the affected area, reconditioning of the cover concrete, and replacing the FRP laminate.

Infrared (IR) thermography can be a fast, reliable and confident non destructive testing technique for the evaluation of bonding defects in FRP - reinforced concrete structures. However, the set - up of an IR technique for the detection of a particular defect (delamination, lack of bonding, ...) in an FRP - reinforced r.c. structure needs a specific calibration, leading to the proper definition of the operational parameters (active/passive approach, distances, time-windows, ...).

The IRT survey calibration was performed in the technological laboratory of CETMA; according to literature indications, some FRP - reinforced concrete samples were accurately prepared, imposing acceptable defects with different shapes and dimensions at the FRP - substrate interface.

Samples were analyzed with pulse heating thermography (PT) and the following parameters were investigated and defined in order to obtain the best defect visibility: thermocamera - sample distance; heating source - sample distance; "impulsive heating" time, or Heating Time; time, after the heating step, at which the thermogram should be recorded, named Observation Time.

After the definition of acceptance criteria and reparation techniques for the defects, a Matlab routine was developed for the thermogram post processing, in order to measure the area of bonding defects at the FRP substrate interface. Only in this way it's possible to establish whether a defect can be acceptable or not, and, in case, what is the best way to repair it.

The developed IRT procedure was applied for quality control of two r.c. structures reinforced with FRP materials. The former, the ex Law Courts of Sant'Angelo dei Lombardi (in the municipal district of Avellino, Italy), retrofitted with GFRP sheets after the catastrophic Irpinia earthquake (magnitude 6.9) of 23rd November, 1980. The latter, an Italian highway r.c. single span bridge structure, seismically upgraded with composite materials according to the Italian law OPCM 3431.

All the installed areas were inspected for defects; summarizing tables were then wrote out (including the indications of site, date, inspected structural elements, non destructive techniques applied and their results, repairing suggestions). In particular, thanks to the developed procedure for thermograms post-processing, each defect was quantified in terms of debonded area and a specific repairing technique was suggested for each defect. Moreover, beyond the indications for each defect, a global opinion about the whole status of the intervention was also given. In some cases, especially when many defects were detected, even if the repairing of every deboned area could be a valuable strategy, the removal and subsequent reapplication of the reinforcement was suggested, in terms of easiness of intervention.

Moreover, for comparative testing, other traditional NDT techniques (visual inspection and coin - tap) were used for the quality control of the FRPs application.

Finally, it can be concluded out that IR thermpography allows a quicker detection not only of all the defects detectable also with other traditional NDTs but also of a set of other smaller defects, otherwise not detectable, but anyhow potentially dangerous for structural safety.

\section{REFERENCES}

[1] Corvaglia P., Manni O., Largo A., Caponero M.A., Galietti U. "Termografia e smart patch in FRP/fibra ottica per la diagnostica ed il monitoraggio di strutture in c.a. rinforzate con FRP" Materiali ed Approcci Innovativi per il Progetto in Zona Sismica e la Mitigazione della Vulnerabilità delle Strutture, Università di Salerno, Febbraio 2007.

[2] Corvaglia P., Manni O., Largo A., Caponero M.A., Galietti U. "Soluzioni innovative per la diagnostica ed il monitoraggio di strutture ed infrastrutture civili: termografia e sensoristica ottica" Monitoraggio di edifici strategici, ponti, gallerie, Napoli, Novembre 2006. 
[3] P. Corvaglia; U. Galietti; A. Largo; S. Nenna; L. Spagnolo, "Feasibility of different thermal analysis of FRP reinforced concrete", QIRT' 06 Padova, June 2006.

[4] U. Galietti, V. Luprano, S. Nenna, L. Spagnolo and A. Tundo. Non-destructive defect characterization of concrete structures reinforced by means of FRP, Advanced Infrared Technology and Applications (AITA), Rome (2005).

[5] CNR-DT 200, "Istruzioni per la progettazione, l'esecuzione ed il controllo di interventi di consolidamento statico mediante l'utilizzo di compositi fibrorinforzati - materiali, strutture di c.a. e di c.a.p., strutture murarie", 2004.

[6] ICC Evaluation Service, Inc., "Interim criteria for inspection and verification of concrete and reinforced and unreinforced masonry strengthening using fibre - reinforced polymer (FRP) composite systems", 2004.

[7] ICC EVALUATION SERVICE, INC. 2003. AC 178 "Interim criteria for inspection and verification of concrete and reinforced and unreinforced masonry strengthening using fibre-reinforced polymer (FRP) composite systems".

[8] Transportation Research Board of the National Academies. 2003. "NCHRP, Report 514: Bonded Repair and Retrofit of Concrete Structures Using FRP Composites - Recommended Construction, Specifications and Process Control Manual". Washington D.C.

[9] J.G. Sun, "Analysis of quantitative measurement of defects by pulsed thermal imaging", Review of QNDE, D.O. Thompson and D.E. Chimenti Eds., 21 (2002) 572-576.

[10] ICBO; "Acceptance criteria for inspection and verification of concrete and reinforced and unreinforced masonry strengthening using fibre-reinforced polymer (FRP) composite systems"; ICBO Evaluation Service, INC, 05/2001.

[11] X.P.V. Maldague; "Theory and Practice of Infrared Technology for Non-destructive Testing"; A WileyInterscience Publication, John Wiley \& Sons Inc.; N.Y. 2001.

[12] A. Muscio; S. Marinetti; P.G. Bison; A. Ciliberto; G. Cavacini and E. Grinzato, "Modelling of Thermal Non Destructive Evaluation Techniques for Composite Materials and the European Aerospace Industry", AITA Advanced Infrared Technology and Applications, Venezia (1999) 143-153.

[13] Peters S.T., "Handbook of Composites", Chapman \& Hall, London (UK), 1998.

[14] D.P. Almond, R. Hamzah, P. Delpech, Peng Wen, M.H. Beheshty, M. B. Saintey; "Experimental investigations of defect sizing by transient thermography"; QIRT 96-Eurotherm Series 50 ETS ed., Pisa 1997, pp.233-238.

[15] X.P.V. Maldague; "Infrared methodology and technology", Gordon and Breach Science Publishers, 1994. 